\title{
Endoscopic Management of Spinal Intradural Extramedullary Tumors
}

\author{
Vijay Singh Parihar ${ }^{1}$ Nishtha Yadav ${ }^{2} \quad$ Yad Ram Yadav $^{1}$ Shailendra Ratre ${ }^{1}$ jitin Bajaj ${ }^{1}$ Yatin Kher $^{1}$ \\ ${ }^{1}$ Department of Neurosurgery, NSCB Medical College and Hospital, \\ Jabalpur, Madhya Pradesh, India \\ 2 Department of Radiodiagnosis and Imaging, All India Institute of \\ Medical Sciences, New Delhi, India

\begin{abstract}
Address for correspondence Yad Ram Yadav, MCh, Department of Neurosurgery, NSCB Medical College and Hospital, 105 Nehru Nagar Opposite Medical College, Jabalpur, MP 482003, India
\end{abstract} \\ (e-mail: yadavyr@yahoo.co.in).
}

J Neurol Surg A 2017;78:219-226.

\begin{abstract}
Keywords

- laminectomy

- minimally invasive surgical procedures

- neuroendoscopy

- operative surgical procedure

- spinal cord neoplasms

Introduction Posterior midline laminectomy is associated with risks of postoperative instability, spinal deformity, extensive bilateral subperiosteal muscle stripping, partial or total facetectomy especially in foraminal tumor extension, increased cerebrospinal fluid leakage, and wound infection. Minimally invasive approaches with the help of a microscope or endoscope using hemilaminectomy have been found to be safe and effective. We report our initial experience of 18 patients using the endoscopic technique.

Material and Methods A retrospective study of intradural extramedullary tumors extending up to two vertebral levels was studied. Pre- and postoperative clinical status, magnetic resonance imaging was done in all patients. The Destandau technique was used, and resection of ipsilateral lamina, medial part of the facet joint, base of the spinous process, and undercutting of the opposite lamina was performed. Dura repair was done using an endoscopic technique. Fibrin glue was used to reinforce repair in the later part of the study.

Results The sagittal and axial diameter of tumor ranged from 21 to $41 \mathrm{~mm}$ and 12 to $18 \mathrm{~mm}$, respectively. There were four cervical, two cervicothoracic, five thoracic, three thoracolumbar, and four lumbar tumors, respectively. All 18 patients improved after total excision of tumor. Average duration of surgery and blood loss was 140 minutes and $60 \mathrm{~mL}$, respectively. Postoperative stay and follow-up ranged from 3 to 7 days and 9 to 24 months, respectively.

Conclusion Although the study is limited by the small number of patients with a short follow-up and is a technically demanding procedure, endoscopic management of intradural extramedullary tumors was an effective and safe alternative technique to microsurgery in such patients.
\end{abstract}

\section{Introduction}

Posterior midline laminectomy has been successfully applied as the standard microsurgical technique for the treatment of spinal intradural pathologies. There are associated risks of postoperative spinal instability and spinal deformity in long-term follow-up. Traditionally the

received

January 2, 2016

accepted after revision

September 14, 2016

published online

December 12, 2016

approach requires bilateral subperiosteal muscle stripping, extensive laminectomy, partial or total facetectomy that could need fusion to prevent deformity (in cases of foraminal extension of tumor), pain, and neurologic deterioration. The open approach also carries an increased risk of postoperative cerebrospinal fluid (CSF) leakage and wound infection due to more dead space.

(c) 2017 Georg Thieme Verlag KG Stuttgart · New York
DOI http://dx.doi.org/ 10.1055/s-0036-1594014. ISSN 2193-6315. 
Minimally invasive approaches for intradural tumors have been found to be safe and effective. ${ }^{1-5}$ A microscope ${ }^{6}$ or endoscope ${ }^{7}$ has been used recently in such cases. Minimally invasive surgical (MIS) approaches using expandable or nonexpandable tubular retractor ${ }^{8}$ or interlaminar approaches ${ }^{9}$ have been described to reduce trauma-related instability with comparable outcome. Unilateral hemilaminectomy for intradural tumors using endoscopic assistance has been used successfully for intradural spinal tumors with preservation of musculoligamentous attachments and posterior bony elements. ${ }^{7}$ We report our initial experience of 18 patients.

\section{Materials and Methods}

This was a retrospective study of intradural extramedullary tumor excision using an endoscopic technique from January 2014 to March 2015. Lesions extending up to two vertebral levels were operated on. Sizes larger than two vertebral segments were excluded. A modified Frankel neurologic functional classification was used for pre- and postoperative clinical assessment. All patients had preoperative magnetic resonance imaging (MRI) (-Fig. 1). Contrast-enhanced MRI was also performed that better demonstrated side, size, and location of the lesion. Preoperative MRI was also done to mark the exact level of lesion when it was difficult to localize the lesion intraoperatively using the $\mathrm{C}$-arm. ${ }^{10}$ Postoperative MRI was performed in all patients 12 weeks after surgery (-Fig. 2). The senior surgeon operated on all patients using the Destandau system (Karl Storz, Tuttlingen, Germany).

\section{Endoscopic Technique}

Surgery was performed in the prone position on a radiolucent table under general anesthesia with the help of a full endo- scopic technique without use of a microscope. The Destandau technique was performed using a 0 -degree endoscope ( $4 \mathrm{~mm}$ diameter and $18 \mathrm{~cm}$ long). The skin incision was made after confirming the level under image guidance using a $\mathrm{C}$-arm or at an already confirmed level using MRI prior to surgery. $\mathrm{A} \sim 2$ to $3-\mathrm{cm}$ skin incision was made $1 \mathrm{~cm}$ away from midline. Fascia was cut just lateral to the midline. Surgical access was created utilizing dilatation technology using stout scissors, finger dissection, and an outer operating sheath with trocar. The operating sheath was directed toward the desired level. Soft tissue on the lamina, facet joint, and ligamentum flavum was removed. Gauge pieces tagged with silk suture were used to push soft tissues and muscle in cranial, caudal, and lateral directions. Ipsilateral laminas, the medial part of the facet if needed, were removed. None of the patients required a complete facetectomy. Base of the spinous process and undercutting of opposite side lamina was performed using a drill. Ligamentum flavum was removed after completion of all bony work (-Fig. 3 ).

The dura mater was opened, and the dural edges were retracted using stay sutures. Tumor removal was accomplished using a bimanual technique. Dural repair and application of dural stay sutures were performed with an endoscope-controlled technique. Fibrin glue was used to reinforce dural repair in the later part of the study in the final 12 patients. It is technically demanding to suture the dura mater in a limited space. Dural repair can be done using full assembly of the Destandau set, or the outer tube of the set can be used as a tubular retractor. An assistant held the endoscope in one corner while the surgeon performed dural repair using a bimanual technique. The telescope holder could also be used to hold the endoscope to allow both hands of surgeon for the procedure. A small size needle $(6 \mathrm{~mm})$ and rotation of hand, as shown in - Fig. 4 , helped in suturing in the limited space. Sufficient bone removal should be done to
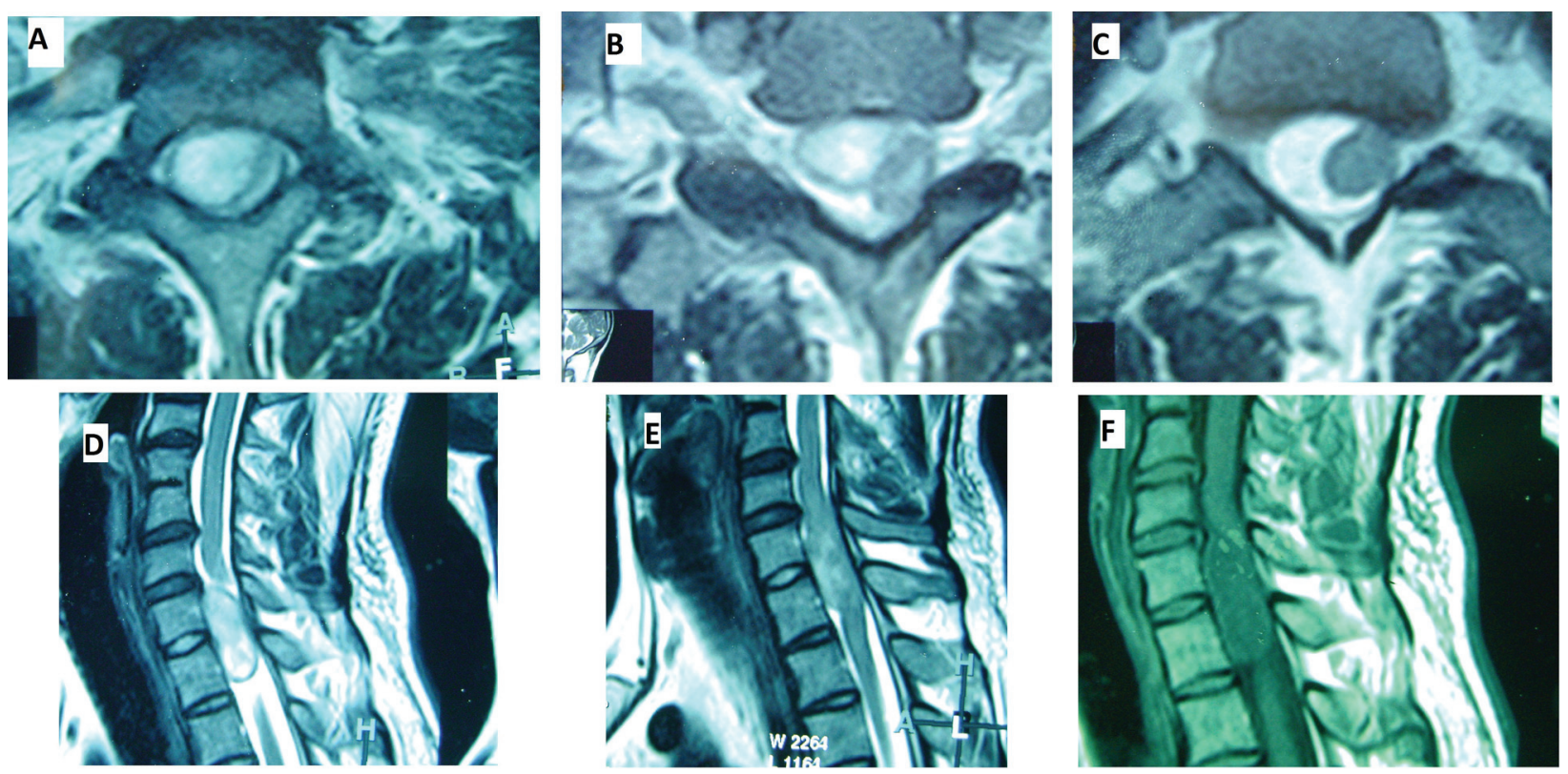

Fig. 1 Preoperative magnetic resonance imaging (A-C) axial and (D-F) sagittal images showing an anterolateral lying intradural extramedullary tumor in the cervicodorsal region. 


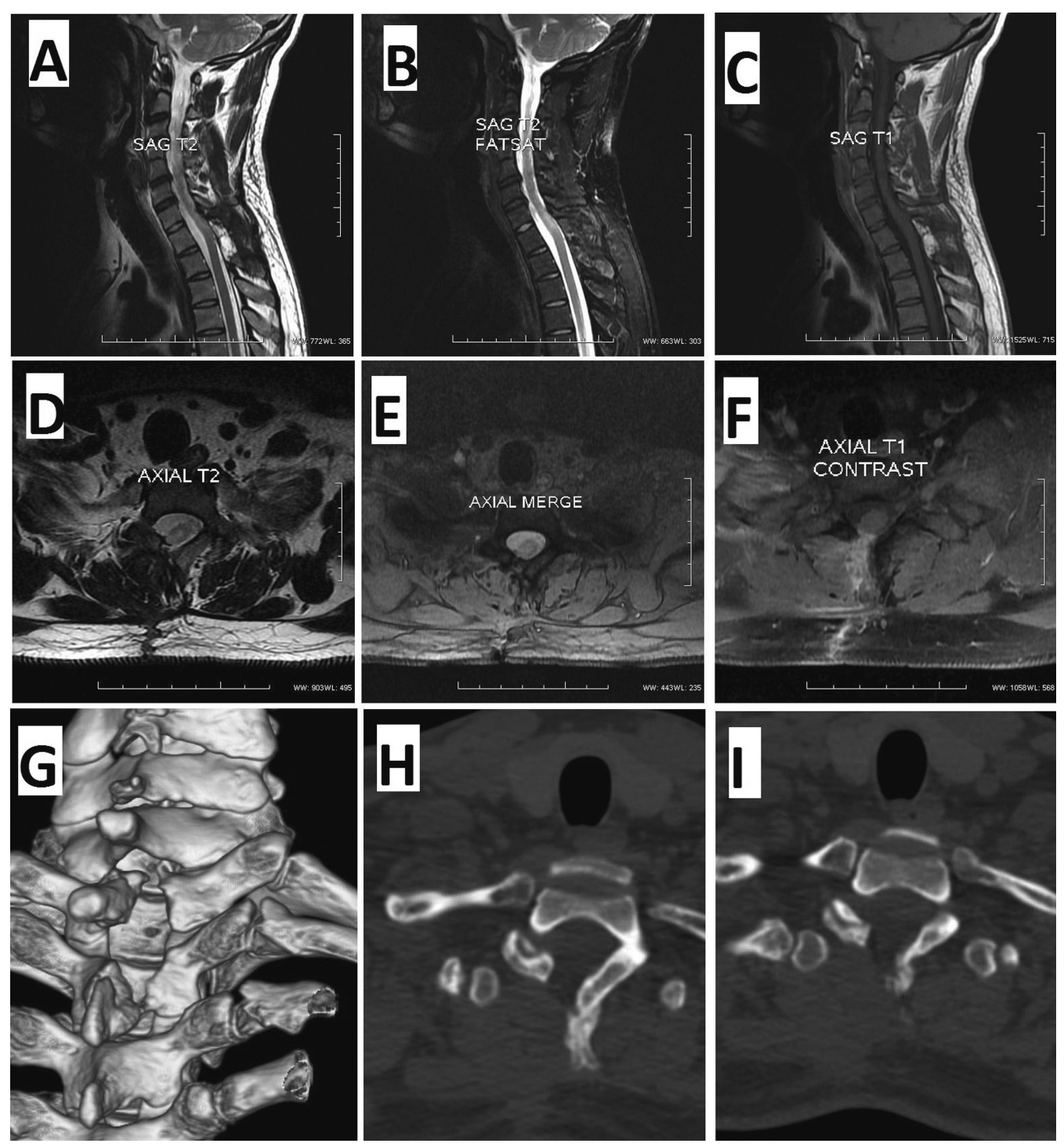

Fig. 2 Postoperative magnetic resonance imaging $(A-C)$ sagittal and $(D-F)$ axial images showing total excision of tumor shown in $\mathbf{- F i g u r e ~} 1$. Reconstructed computed tomography $(\mathrm{CT})$ scan image $(\mathrm{G})$ and axial $\mathrm{CT}$ cuts $(\mathrm{H}, \mathrm{I})$ showing hemilaminectomy.

allow needle movement. It is advisable to remove the bone toward the base of the spinous process and contralateral lamina to avoid damage to the ipsilateral facet joint.

Tumor dissection and dural suturing could be very difficult in the presence of bleeding. Absolute hemostasis should be achieved before proceeding to the next step during surgery. Head end elevation, cold or warm saline irrigation, keeping a small piece of Abgel (Shri Gopal Krishna Labs Pvt. Ltd. Mumbai, India) or Surgicel (Ethicon Johnson House, Mumbai, India) between the dura and bone, use of bipolar cautery, and use of Floseal (Baxter Healthcare, Round Lake, Illinois, United States) stops bleeding in most cases.

\section{Results}

Age of patients ranged from 21 to 58 years (average: 43 years) (-Table 1). There were eight female patients. Duration of symptoms varied from 7 months to 21 months (average: 15.9 months). Modified Frankel neurologic functional classifications were used for pre- and postoperative clinical assessment. There were seven patients (modified Frankel grade D 3c) who were ambulatory with some neurologic deficits, but they could walk independently without any support and with normal bladder and bowel functions preoperatively. Five patients (modified Frankel grade D 2c) were ambulatory but required cane support to walk with normal bladder and bowel functions. Two patients (modified Frankel grade D 1c) were ambulatory but required a walker with normal bladder and bowel functions. Three patients (modified Frankel grade $D 1 b$ ) were ambulatory but required a walker with neurogenic bladder and bowel functions. There was one patient (modified Frankel grade $\mathrm{C}$ c) who was wheelchair bound with normal bladder and bowel functions.

All patients improved to normal neurologic functions (modified Frankel grade E) after surgery at follow-up except one patient who was wheelchair bound preoperatively. He also improved and became ambulatory and could walk independently without any support with normal bladder and bowel functions (modified Frankel grade D 3c). 

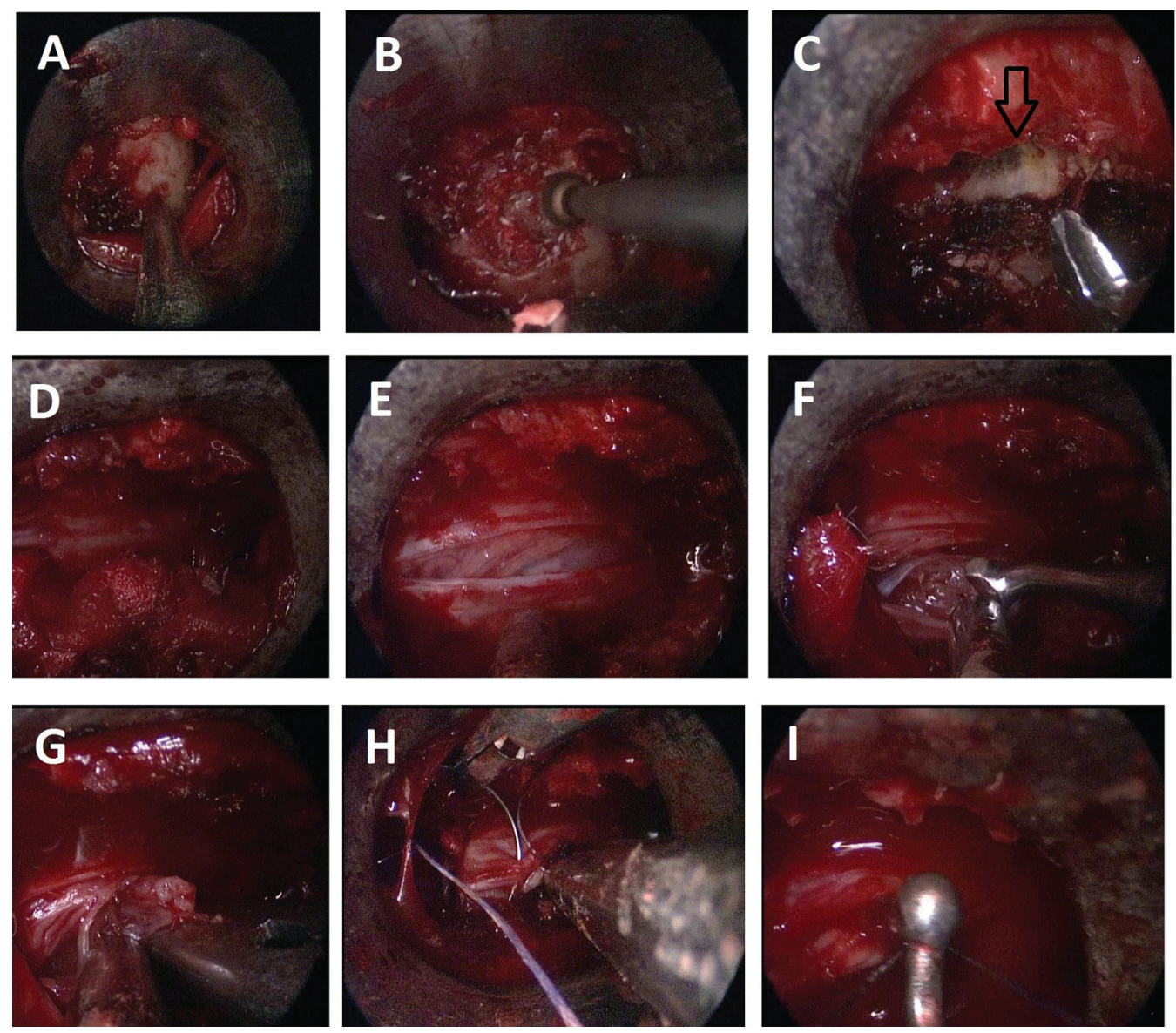

Fig. 3 Endoscopic images showing exposure of lamina (A), drilling of ipsilateral lamina (B), and undercutting of contralateral lamina (arrow) (C), exposure of thecal sac after removal of bone and ligamentum flavum (D), dural incision (E), removal of tumor using bimanual technique (F, G), direct repair of dura mater using fine needle $(\mathrm{H})$, and knot pusher (I) for dural suturing.

Sagittal and axial diameter of the tumors ranged from 21 to $41 \mathrm{~mm}$ and 12 to $18 \mathrm{~mm}$, respectively. Preoperative MRI localization was used in all cases of dorsal or dorsolumbar pathology. There were four cervical, two cervicothoracic, five thoracic, three thoracolumbar, and four lumbar tumors. The tumors were located anterolaterally in 3 patients; 15 patients had dorsal or dorsolateral lesions. There were 13 schwannomas and 5 meningiomas. Total excision was achieved in all patients. The average duration of surgery and average blood loss was 140 minutes (range: $90-180$ minutes) and $60 \mathrm{~mL}$ (range: $30-350 \mathrm{ml}$ ), respectively. There was no instability, CSF leak, or infection.

Postoperative stay in the hospital ranged from 3 to 7 days. In the initial six cases we kept patients in bed for 3 days, but in later parts of the study we used tissue glue along with direct dural repair, which allowed patients to begin early ambulation on postoperative day 1 . Follow-up ranged from 9 months to 24 months.

\section{Discussion}

Endoscopy is being used increasingly in spine, ${ }^{11-13}$ skull base, ${ }^{14-16}$ and cranial surgery. ${ }^{17-20}$ It is also useful for various types of pathologies such as congenital lesions, ${ }^{21,22}$ hematoma evacuation, ${ }^{23-25}$ tumor excisions, ${ }^{26-28}$ and for infective pathologies. ${ }^{29,30}$ Endoscopic technique for intradural extramedullary spinal tumor removal has been found to be safe and effective in our series. Similarly, MIS technique by hemilaminectomy for intradural spinal tumor has been described using microscopic ${ }^{31}$ or endoscopic approaches ${ }^{7}$ with a good clinical outcome. The results of the minimally invasive approach were comparable with the open technique. ${ }^{32,33}$

The average operative time and blood loss in our study was 140 minutes and $60 \mathrm{~mL}$, respectively. Operative time and tumor resection rates have been reported to be similar between MIS and the open approach. ${ }^{34}$ Estimated blood loss and mean hospital stay have been reported to be significantly less in the MIS group compared with the open group. ${ }^{34}$

We could remove tumors in various locations including cervical, cervicothoracic, thoracic, thoracolumbar, and lumbar regions. Similarly, tumors from the occipital-cervical junction, cervical, cervicodorsal, dorsal, dorsolumbar, lumbar, and lumbosacral could be removed successfully. ${ }^{35}$ We could also remove tumors located anterolaterally in our series. Although the anterior ${ }^{36}$ or anterolateral approaches ${ }^{37}$ can be used in anterolaterally lying tumors, the endoscope can obviate the use of the anterior approach because it allows removal of tumor with better visualization using minimal 


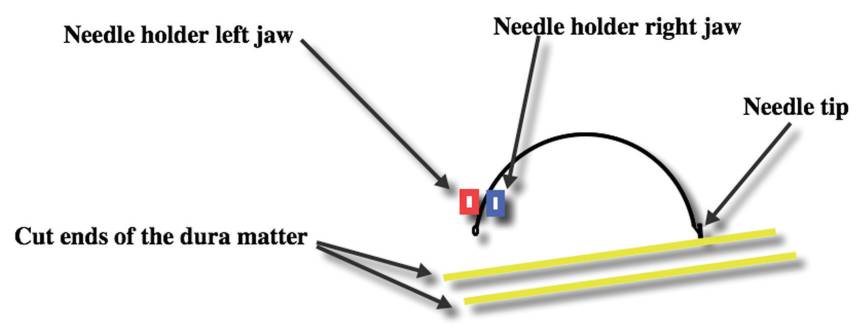

A: Position of needle almost parallel to dural cut ends, please note position of jaws of needle holder

B: Clock wise rotation of needle holder and slight movement towards suture entry point in dura allows entry of needle in atleast one cut edge of dura matter, please note position of jaws of neddle holder

Fig. 4 Line drawing showing how to repair the dura in a limited space. Where any linear movement is difficult, rotation movement is helpful. (A) Needle should be brought parallel to the cut end of the dura. (B) This needle should be rotated in such a way that it passes through the cut end of the dura. The needle can be lifted up away from the facet joint or pars bone to permit unobstructed movement.

retraction of the spinal cord. ${ }^{38}$ We could remove all tumors totally including those lying anterior to the cord in our series. Similarly, total resection of anterior and anterolateral lesions accomplished without introducing new neurologic deficits was reported with a posterior approach through a singlesided keyhole laminotomy. ${ }^{39}$

Although microscopic technique using tubular retractor is equally effective, the endoscope could have the additional advantage of better visualization, especially for the ventrally located part of the tumor. The endoscope assisted in identifying a residual spinal cord tumor due to better visualization. ${ }^{40}$ Less soft tissue disruption, significant decreased dead space, decreased rate of CSF leak, ${ }^{41}$ and preservation of facet joints with spinal stability associated with the endoscopic approach could also be achieved by the microscopic technique using a tubular retractor. This minimally invasive approach can eliminate the need for facetectomy even in cases of foraminal tumors, which can decrease the incidence of postoperative deformity and eliminate the need for adjunctive fusion surgery. ${ }^{8}$ Postoperative spinal stability for singlelevel hemilaminectomy was found to be good; however, in one report, fusion was advocated in the involvement of two or more spinal segments. ${ }^{42}$ Although we did not come across instability in our series even after two levels of hemilaminectomy, that could be due to intact bilateral facet joints, intact opposite side lamina, preservation of most of soft tissue support of the spine, and so on. There is a report that even multilevel hemilaminectomy greatly preserved the flexion motion of $>48 \%$ of spine compared with laminectomy. Hemilaminectomy not only preserves the motion and postoperative spinal stability but also reduces the stress and lowers the risk of postoperative disk degeneration. ${ }^{43}$

Although endoscopic approaches have many advantages, they are also associated with some limitations such as difficulties in tumor localization, removal of a large tumor, primary dural suturing, control of bleeding, a steep learning curve, and difficulties in bimanual dissection. Exact level of the localization of the lesion may be difficult intraoperatively, especially in the thoracic region. Preoperative localization used to guide the level of hemilaminectomy was accurate, quick, safe, reduced operative time, was cost effective, and noninvasive with no exposure to radiation. ${ }^{10}$ Larger lesions of more than two vertebral segments are difficult to treat using the endoscopic technique. Maximum lengths of tumor were $4 \mathrm{~cm}$ in the series by $\mathrm{Gu}$ et al where they used hemilaminectomy and microsurgical technique. ${ }^{44}$ Haji et al also removed 
Table 1 Demography, site of lesion, clinical features, type of pathologies, surgery, and outcome of intradural extramedullary tumors

\begin{tabular}{|c|c|c|c|c|c|}
\hline $\begin{array}{l}\text { Serial } \\
\text { no. }\end{array}$ & $\begin{array}{l}\text { Age, } \\
\text { y/Sex }\end{array}$ & Site of lesion & Clinical features & Type of surgery & Outcome \\
\hline 1 & $35 / \mathrm{M}$ & Thoracic & $\begin{array}{l}\text { Progressive paraparesis for } 15 \mathrm{mo} \\
\text { Frankel grade D 3c }\end{array}$ & Total excision of schwannoma & Improved to Frankel grade $\mathrm{E}$ \\
\hline 2 & $54 / F$ & Cervical & $\begin{array}{l}\text { Progressive quadriparesis for } 11 \mathrm{mo} \\
\text { Frankel grade D 1b }\end{array}$ & Total excision of meningioma & Improved to Frankel grade $\mathrm{E}$ \\
\hline 3 & $47 / M$ & Thoracolumbar & $\begin{array}{l}\text { Progressive paraparesis for } 18 \mathrm{mo} \\
\text { Frankel grade D 3c }\end{array}$ & Total excision of schwannoma & Improved to Frankel grade $\mathrm{E}$ \\
\hline 4 & $42 / \mathrm{M}$ & Cervicothoracic & $\begin{array}{l}\text { Progressive quadriparesis for } 7 \mathrm{mo} \\
\text { Frankel grade D 3c }\end{array}$ & Total excision of meningioma & Improved to Frankel grade $\mathrm{E}$ \\
\hline 5 & $38 / \mathrm{F}$ & Lumbar & $\begin{array}{l}\text { Progressive paraparesis for } 21 \mathrm{mo} \\
\text { Frankel grade C c }\end{array}$ & Total excision of schwannoma & Improved to Frankel grade D $3 \mathrm{C}$ \\
\hline 6 & $21 / \mathrm{M}$ & Cervical & $\begin{array}{l}\text { Progressive quadriparesis for } 19 \text { mo } \\
\text { Frankel grade D 1b }\end{array}$ & Total excision of meningioma & Improved to Frankel grade $\mathrm{E}$ \\
\hline 7 & $39 / \mathrm{M}$ & Thoracolumbar & $\begin{array}{l}\text { Progressive paraparesis for } 17 \mathrm{mo} \\
\text { Frankel grade D 3c }\end{array}$ & Total excision of schwannoma & Improved to Frankel grade $\mathrm{E}$ \\
\hline 8 & $52 / F$ & Thoracic & $\begin{array}{l}\text { Progressive paraparesis for } 16 \text { mo } \\
\text { Frankel grade D 2c }\end{array}$ & Total excision of meningioma & Improved to Frankel grade $\mathrm{E}$ \\
\hline 9 & $41 / \mathrm{F}$ & lumbar & $\begin{array}{l}\text { Progressive paraparesis for } 18 \mathrm{mo} \\
\text { Frankel grade D 3c }\end{array}$ & Total excision of schwannoma & Improved to Frankel grade $\mathrm{E}$ \\
\hline 10 & $53 / \mathrm{M}$ & Cervical & $\begin{array}{l}\text { Progressive quadriparesis for } 14 \text { mo } \\
\text { Frankel grade D 1b }\end{array}$ & Total excision of schwannoma & Improved to Frankel grade $\mathrm{E}$ \\
\hline 11 & $50 / F$ & Thoracic & $\begin{array}{l}\text { Progressive paraparesis for } 16 \text { mo } \\
\text { Frankel grade D 2c }\end{array}$ & Total excision of meningioma & Improved to Frankel grade $\mathrm{E}$ \\
\hline 12 & $58 / \mathrm{M}$ & Lumbar & $\begin{array}{l}\text { Progressive paraparesis for } 19 \mathrm{mo} \\
\text { Frankel grade D 1c }\end{array}$ & Total excision of schwannoma & Improved to Frankel grade $\mathrm{E}$ \\
\hline 13 & $47 / M$ & Cervicothoracic & $\begin{array}{l}\text { Progressive quadriparesis for } 17 \text { mo } \\
\text { Frankel grade D } 3 c\end{array}$ & Total excision of schwannoma & Improved to Frankel grade $\mathrm{E}$ \\
\hline 14 & $29 / F$ & Lumbar & $\begin{array}{l}\text { Progressive paraparesis for } 15 \text { mo } \\
\text { Frankel grade D 2c }\end{array}$ & Total excision of schwannoma & Improved to Frankel grade $\mathrm{E}$ \\
\hline 15 & $46 / \mathrm{M}$ & Thoracic & $\begin{array}{l}\text { Progressive paraparesis for } 19 \text { mo } \\
\text { Frankel grade D 2c }\end{array}$ & Total excision of schwannoma & Improved to Frankel grade $\mathrm{E}$ \\
\hline 16 & $36 / \mathrm{M}$ & Cervical & $\begin{array}{l}\text { Progressive quadriparesis } \\
14 \text { mo } \\
\text { Frankel grade D 3c }\end{array}$ & Total excision of schwannoma & Improved to Frankel grade $\mathrm{E}$ \\
\hline 17 & $42 / \mathrm{F}$ & Thoracic & $\begin{array}{l}\text { Progressive paraparesis for } 13 \mathrm{mo} \\
\text { Frankel grade D 2c }\end{array}$ & Total excision of schwannoma & Improved to Frankel grade $\mathrm{E}$ \\
\hline 18 & $39 / F$ & Thoracolumbar & $\begin{array}{l}\text { Progressive paraparesis for } 17 \mathrm{mo} \\
\text { Frankel grade } \mathrm{D} 1 \mathrm{c}\end{array}$ & Total excision of schwannoma & Improved to Frankel grade $\mathrm{E}$ \\
\hline
\end{tabular}

Abbreviations: F, female; M, male.

lesions up to two spinal levels using a minimally invasive approach. ${ }^{45}$ We also removed tumors extending up to two levels only. The primary dural closure in endoscopic technique in intradural tumors can be technically challenging due to a limited surgical corridor, which may force surgeons to consider prolonged bed rest. We also used 3 days of bed rest in the initial period. Prolonged bed rest appears unnecessary after gaining sufficient experience in watertight dural closure. ${ }^{46}$ Fibrin glue can be used to reinforce dural repair.

Tumor dissection and dural suturing can be very difficult in the presence of bleeding. Absolute hemostasis should be achieved before proceeding to the next step during surgery. Head end elevation, cold or warm saline irrigation, keeping a small piece of Abgel or Surgicel between dura and bone, use of bipolar cautery, and use of Floseal stops bleeding in most cases. Although we have used hot saline in our patients for hemostasis, ice-cold saline is also very effective. Several different mechanisms for hemostasis using hot saline have been proposed including activation of platelet aggregation, enhanced coagulation, and interstitial edema. Cold saline irrigation $\left(\sim 4^{\circ} \mathrm{C}\right)$ is also effective in hemostasis. It acts mainly by vasoconstriction apart from activation of platelet aggregation. Diffuse low-flow bleeding from soft tissues and bone responds very well to warm saline irrigation. High-flow bleeding from arterial or venous origin does not respond to hot or cold irrigation techniques. Bleeding can be controlled with the help of a microscope using the outer sheath of the endoscopic system as a tubular retractor as a last resort, although we did not require this technique in the present series.

Such surgeries are technically difficult and should be performed after gaining sufficient experience in other simple endoscopic techniques such as lumbar disk and endoscopic third ventriculostomy. Endoscopic skill using bimanual dissection, hemostasis, and suturing can be learned by attending 
live operative workshops, cadaveric dissection, watching operative videos, visiting other departments, and watching skillful neuroendoscopic surgeons. ${ }^{47}$ Proper patient selection of simpler cases in the beginning and use of simulators can shorten the learning curve.

Using the bimanual technique could be difficult, especially in the limited space available. Existing endoscopic systems also pose difficulties when one needs to work in the presence of oozing where more than two instruments are required. Bimanual technique is essential for dissection of tumor from spinal cord or root and also for hemostasis. Dural suturing also requires the bimanual technique.

It is technically demanding to suture in a limited space. Small needle size $(6 \mathrm{~mm})$, rotation of hand rather than linear movement, and needle movement initially at 90 degrees to the dural edge and then in the direction of more space (should not be obstructed by facet joint or any other bony structure) are useful for dural suturing. Availability of better instruments in the future such as a slender Covidien Endo Stitch (Medtronic, Minneapolis, Minnesota, United States) and other developments in endoscopic surgery will help improve dural repair. Sufficient bone removal should be done to allow needle movement. More bone removal should be toward the base of the spinous process and opposite lamina to avoid damage to the facet joint.

\section{References}

1 Konovalov NA, Shevelev IN, Nazarenko AG, et al. The use of minimally invasive approaches to resect intradural extramedullary spinal cord tumors. [in Russian]. Vopr Neirokhir 2014;78:24-34

2 Gandhi RH, German JW. Minimally invasive approach for the treatment of intradural spinal pathology. Neurosurg Focus 2013;35(2):E5

3 Tan LA, Kasliwal MK, Wewel J, Fontes RB, O’Toole JE. Minimally invasive surgery for synchronous, same-level lumbar intraduralextramedullary neoplasm and acute disc herniation. Neurosurg Focus 2014;37(Suppl 2):16

4 Lu DC, Chou D, Mummaneni PV. A comparison of mini-open and open approaches for resection of thoracolumbar intradural spinal tumors. J Neurosurg Spine 2011;14(6):758-764

5 Mannion RJ, Nowitzke AM, Efendy J, Wood MJ. Safety and efficacy of intradural extramedullary spinal tumor removal using a minimally invasive approach. Neurosurgery 2011;68(1, Suppl Operative):208-216; discussion 216

6 Tredway TL, Santiago P, Hrubes MR, Song JK, Christie SD, Fessler RG. Minimally invasive resection of intradural-extramedullary spinal neoplasms. Neurosurgery 2006;58,(1 Suppl):ONS52-ONS58; discussion ONS52-ONS58

7 Mobbs RJ, Maharaj MM, Phan K, Rao PJ. Unilateral hemilaminectomy for intradural lesions. Orthop Surg 2015;7(3):244-249

8 Nzokou A, Weil AG, Shedid D. Minimally invasive removal of thoracic and lumbar spinal tumors using a nonexpandable tubular retractor. J Neurosurg Spine 2013;19(6):708-715

9 Zhu YJ, Ying GY, Chen AQ et al. Minimally invasive removal of lumbar intradural extramedullary lesions using the interlaminar approach. Neurosurg Focus 2015;39(2):E10

10 Turel MK, Rajshekhar V. Magnetic resonance imaging localization with cod liver oil capsules for the minimally invasive approach to small intradural extramedullary tumors of the thoracolumbar spine. J Neurosurg Spine 2014;21(6):882-885
11 Yadav YR, Parihar V, Namdev H, Agarwal M, Bhatele PR. Endoscopic interlaminar management of lumbar disc disease. J Neurol Surg A Cent Eur Neurosurg 2013;74(2):77-81

12 Nomura K, Yoshida M, Kawai M, Okada M, Nakao S. A novel microendoscopically assisted approach for the treatment of recurrent lumbar disc herniation: transosseous discectomy surgery. J Neurol Surg A Cent Eur Neurosurg 2014;75(3):183-188

13 Yadav YR, Madhariya SN, Parihar VS, Namdev H, Bhatele PR. Endoscopic transoral excision of odontoid process in irreducible atlantoaxial dislocation: our experience of 34 patients. J Neurol Surg A Cent Eur Neurosurg 2013;74(3):162-167

14 Tabaee A, Kamat A, Shrivastava R. Complex reconstruction of the sella using absorbable mini-plate in revision endoscopic pituitary surgery: technical note. J Neurol Surg A Cent Eur Neurosurg 2013; 74(5):313-317

15 Iannelli A, Lenzi R, Muscatello L. A useful maneuver to simplify sellar floor repair following endoscopic transnasal pituitary surgery. J Neurol Surg A Cent Eur Neurosurg 2014;75(2):158-160

16 Duque SG, Gorrepati R, Kesavabhotla K, Huang C, Boockvar JA. Endoscopic endonasal transphenoidal surgery using the Brain$L A B \circledast$ Headband for navigation without rigid fixation. J Neurol Surg A Cent Eur Neurosurg 2014;75(4):267-269

17 Yadav YR, Parihar VS, Ratre S, Kher Y. Avoiding complications in endoscopic third ventriculostomy. J Neurol Surg A Cent Eur Neurosurg 2015;76(6):483-494

18 Setty P, D’Andrea KP, Stucken EZ, Babu S, LaRouere MJ, Pieper DR. Fully endoscopic resection of cerebellopontine angle meningiomas. J Neurol Surg A Cent Eur Neurosurg 2016;77(1):11-18

19 Beer-Furlan A, Pinto F, Teixeira M, Rigante L, Evins AI, Bernardo A. Endoscopic fenestration of the lamina terminalis: alternatives to the classic third ventriculostomy. J Neurol Surg A Cent Eur Neurosurg 2014;75(5):410-412

20 Herrada-Pineda T, Revilla-Pacheco F, Manrique-Guzman S. Endoscopic approach for the treatment of pineal region tumors. J Neurol Surg A Cent Eur Neurosurg 2015;76(1):8-12

21 Raju S, Sharma RS, Moningi S, Momin J. Neuroendoscopy for intracranial arachnoid cysts in infants: therapeutic considerations. J Neurol Surg A Cent Eur Neurosurg 2016;77(4):333-343

22 Banczerowski P, Czigléczki G, Gádor I, Nyáry I. Long-term outcome of endonasal transsphenoidal approach for the treatment of pontine cavernous malformation: Case report with 11 years of follow-up. J Neurol Surg A Cent Eur Neurosurg 2016;77(3): 269-273

23 Ochalski P, Chivukula S, Shin S, Prevedello D, Engh J. Outcomes after endoscopic port surgery for spontaneous intracerebral hematomas. J Neurol Surg A Cent Eur Neurosurg 2014;75(3): 195-205; discussion 206

24 Nakatogawa H, Tanaka T, Inenaga C, Fujimoto A, Yamamoto T. Endoscopic removal of neonatal acute epidural hematoma via strip-bending osteoplastic craniotomy. Technical note. J Neurol Surg A Cent Eur Neurosurg 2015;76(6):495-498

25 Ueba T, Yasuda M, Inoue T. Endoscopic burr hole surgery with a curettage and suction technique to treat traumatic subacute subdural hematomas. J Neurol Surg A Cent Eur Neurosurg 2015; 76(1):63-65

26 Yadav YR, Parihar V, Pande S, Namdev H. Endoscopic management of colloid cysts. J Neurol Surg A Cent Eur Neurosurg 2014;75(5): 376-380

27 Ratre S, Yadav YR, Parihar VS, Kher Y. Microendoscopic removal of deep-seated brain tumors using tubular retraction system. J Neurol Surg A Cent Eur Neurosurg 2016;77(4):312-320

$28 \mathrm{Hu} \mathrm{Z}$, Guan F, Kang T, et al. Whole course neuroendoscopic resection of cerebellopontine angle epidermoid cysts. J Neurol Surg A Cent Eur Neurosurg 2016;77(5):381-388

29 Yadav YR, Sinha M, Parihar V; Neha. Endoscopic management of brain abscesses. Neurol India 2008;56(1):13-16 
30 Yadav YR, Parihar V, Agrawal M, Bhatele PR. Endoscopic third ventriculostomy in tubercular meningitis with hydrocephalus. Neurol India 2011;59(6):855-860

31 Turel MK, D’Souza WP, Rajshekhar V. Hemilaminectomy approach for intradural extramedullary spinal tumors: an analysis of 164 patients. Neurosurg Focus 2015;39(2):E9

32 Raygor KP, Than KD, Chou D, Mummaneni PV. Comparison of minimally invasive transspinous and open approaches for thoracolumbar intradural-extramedullary spinal tumors. Neurosurg Focus 2015;39(2):E12

33 Pompili A, Caroli F, Cattani F, et al. Unilateral limited laminectomy as the approach of choice for the removal of thoracolumbar neurofibromas. Spine 2004;29(15):1698-1702

34 Wong AP, Lall RR, Dahdaleh NS, et al. Comparison of open and minimally invasive surgery for intradural-extramedullary spine tumors. Neurosurg Focus 2015;39(2):E11

35 Feldman M, Kimmell KT, Replogle RE. Resection of an occipitalcervical junction schwannoma through a modified minimally invasive approach: Technical Note. Surg Neurol Int 2015;6 (Suppl 4):S177-S181

36 Jho HD, Ha HG. Anterolateral approach for cervical spinal cord tumors via an anterior microforaminotomy: technical note. Minim Invasive Neurosurg 1999;42(1):1-5

37 Yasuda M, Bresson D, Cornelius JF, George B. Anterolateral approach without fixation for resection of an intradural schwannoma of the cervical spinal canal: technical note. Neurosurgery 2009;65(6):1178-1181; discussion 1181

38 Barami K, Dagnew E. Endoscope-assisted posterior approach for the resection of ventral intradural spinal cord tumors: report of two cases. Minim Invasive Neurosurg 2007;50(6): 370-373

39 Kaya RA. Surgical excision of spinal intradural meningiomas through a single-sided minimally invasive approach: key-hole laminotomy. Asian Spine J 2015;9(2):225-231

40 Chern JJ, Gordon AS, Naftel RP, Tubbs RS, Oakes WJ, Wellons JC III. Intradural spinal endoscopy in children. J Neurosurg Pediatr 2011; 8(1):107-111

41 Lee B, Hsieh PC. Minimally invasive lumbar intradural extramedullary tumor resection. Neurosurg Focus 2012;33(Suppl 1):1

42 Zong S, Zeng G, Du L, Fang Y, Gao T, Zhao J. Treatment results in the different surgery of intradural extramedullary tumor of 122 cases. PLoS One 2014;9(11):e111495

43 Xie T, Qian J, Lu Y, Chen B, Jiang Y, Luo C. Biomechanical comparison of laminectomy, hemilaminectomy and a new minimally invasive approach in the surgical treatment of multilevel cervical intradural tumour: a finite element analysis. Eur Spine J 2013; 22(12):2719-2730

44 Gu R, Liu JB, Xia P, Li C, Liu GY, Wang JC. Evaluation of hemilaminectomy use in microsurgical resection of intradural extramedullary tumors. Oncol Lett 2014;7(5):1669-1672

45 Haji FA, Cenic A, Crevier L, Murty N, Reddy K. Minimally invasive approach for the resection of spinal neoplasm. Spine $2011 ; 36(15)$ : E1018-E1026

46 Tan LA, Takagi I, Straus D, O’Toole JE. Management of intended durotomy in minimally invasive intradural spine surgery: clinical article. J Neurosurg Spine 2014;21(2):279-285

47 Yadav YR, Parihar V, Ratre S, Kher Y, Iqbal M. Microneurosurgical skills training. J Neurol Surg A Cent Eur Neurosurg 2016;77(2):146-154 